\title{
Luxation injuries in primary teeth: a retrospective study in children assisted at an emergency service
}

\section{Luciana Reichert da Silva Assunção(a) Antônio Ferelle(b) Maria Luiza Hiromi Iwakura ${ }^{(b)}$ Liliane Silva do Nascimento(a) Robson Frederico Cunha(c)}

(a) Department of Clinic, School of Dentistry, Federal University of Pará, UFPA, Belém, PA, Brazil.

(b) Department of Oral Medicine and Pediatric Dentistry, Londrina State University, Londrina, PR, Brazil.

(c) Department of Pediatric Dentistry, School of Dentistry, UNESP - Univ Estadual Paulista, Araçatuba, SP, Brazil.

\section{Corresponding author}

Luciana Reichert da Silva Assunção

School of Dentistry, Federal University of Pará - UFPA

Rua Augusto Corrêa, 01

CEP: 66075-900

Belém - PA - Brazil

E-mail: lurassuncao@yahoo.com.br

Received for publication on Oct 14, 2010 Accepted for publication on Feb 15, 2011

\begin{abstract}
The purpose of this study was to analyze luxation injuries in children between the ages of 0 and 5 years treated at an emergency service department. A total of 1,703 records, corresponding to a period of 10 years at the Emergency Center of the Baby Clinic at Londrina State University, Brazil, were analyzed. The age, gender, etiologic factors, type of injury, injured teeth, treatment and time interval between injury and treatment were determined for each patient. Of the examined records, 409 patients met the study criteria and included a total of 679 injured teeth. Statistical analyses were carried out using the chi-square test with the level of significance set at 5\%. Trauma incidence was higher in boys $(57.0 \%)$ and in children less than two years of age $(40.3 \%)$. Falling while walking or running was the most predominant etiologic factor $(37.7 \%)$, and the most prevalent type of injury was subluxation (32.6\%). Luxation injuries decreased with increasing age $(p=0.045)$. Treatment usually occurred within the first 1-15 days and was significantly associated with the type of trauma ( $p=0.041$ ). "Monitor only" was the treatment most frequently observed $(74.0 \%)$. In conclusion, more luxation injuries were found in younger children, predominantly in boys. Falls resulting from walking or running were the etiologic factor most observed, with subluxation as the most common type of trauma. Treatment usually occurred within the first 15 days after the injury. Despite the severity of these injuries, "monitor only" was the eligible treatment.
\end{abstract}

Descriptors: Tooth injuries; Tooth, Deciduous; Tooth Avulsion; Child.

\section{Introduction}

Dental trauma is a serious public health problem among children, with most injuries constituting dental emergencies that require immediate assessment and management. Luxation injuries that affect the primary dentition are commonly reported and are associated with resilience of the alveolar bone and supporting structures in young children. ${ }^{1}$

Primary dentition plays an important role in the functional and psychological aspects of child development, which may contribute to new studies focused on trauma in the primary dentition. ${ }^{2}$ Additionally, researchers unanimously agree that dental trauma to primary teeth can lead to alterations in the succedaneous dentition, especially in cases of intrusive luxation and avulsion. ${ }^{3}$

The introduction of a dental practice for toddlers and babies in the 
field of Pediatric Dentistry may contribute to a variety of new studies about trauma in the primary dentition. ${ }^{2}$ Based on a preventive-educational philosophy, this field has created specialized centers for children between the ages of 0 and 3 years, with a special focus on dental trauma. ${ }^{4}$ Cunha et al. ${ }^{4}$ studied 1,654 pediatric patients at the Baby Clinic of the Araçatuba Dental School, UNESP, Brazil, and observed a $16.3 \%$ occurrence of dental trauma.

Similar to the preventative-educational program, the Baby Clinic at Londrina State University, Brazil, offers urgent care treatment for children ranging in age from $0-5$ years. The purpose of this study was, therefore, to analyze primary tooth luxation injuries in children treated at the Emergency Center of the Baby Clinic at Londrina State University by investigating the age, gender, etiologic factors, type of injury, injured teeth, treatment and time interval between injury and treatment.

\section{Material and methods}

The records of 1,703 children, seen over the course of 10 years at the Emergency Center of the Baby Clinic at Londrina State University, Brazil, were analyzed. Criteria for inclusion in this study included:

a. a description of trauma to the anterior primary teeth;

b. age of the children in the moment of injury was up to five years;

c. trauma associated with subluxation, intrusive luxation, lateral luxation, extrusive luxation and avulsion, according to Andreasen et al. ${ }^{1}$

After analyzing 1,703 medical records, 409 $(24 \%)$ patients met the inclusion criteria. Twenty of the children $(4.8 \%)$ presented with more than a single occurrence of trauma to primary teeth; within this group, 17 patients reported two occurrences and three patients reported three episodes of dental trauma in their medical records. In total, 409 children suffered 432 occurrences of dental trauma. Medical records were analyzed to obtain dental trauma information and to determine the following factors: gender, age of the child at the time of trauma, type of injury, etiologic factors, injured teeth, treatment and the time interval between injury and treatment.

\section{Children's age at the time of trauma}

The children were divided into the following groups according to their age at the time of trauma:

- up to 2 years;

- 2-3 years;

- 3-4 years; and

- 4-5 years.

\section{Etiologic factors}

The causes of the injuries were grouped as follows:

- 'category 1' (falls) and

- 'category 2' (other factors).

'Category 1' were further delineated into the following sub-categories:

- falling while walking or running,

- falling from a high place (e.g., bed, gate, cot),

- falling onto an object (e.g., table, bathtub, stairs) and

- falling from a moving object (e.g., bike, pram).

'Category 2' factors included causes that were rare and more difficult to categorize, such as trauma caused by biting a toy.

\section{Treatment}

The following types of treatment provided to the traumatized teeth were evaluated: monitor only, prosthesis installation, extraction, splinting, repositioning, and repositioning and splinting. The treatments that were given as a result of the sequelae of dental trauma (i.e., endodontic treatment and delayed extraction) were not evaluated, resulting in the exclusion of 101 traumatized teeth.

\section{Time elapsed before treatment}

The time period between injury and treatment was divided into the following categories:

- 1 day,

- 2-15 days,

- 16-30 days and

- greater than 30 days. $^{5}$

For the analysis of this variable and the type of trauma, the intervals were divided into 1-15 days 
and more than 16 days. Sixty-seven traumatized teeth were excluded from this analysis due to a lack of information regarding the time interval.

\section{Statistical analyses}

The results were statistically analyzed using the chi-square $\left(\chi^{2}\right)$ test, with the level of significance set at $5 \%$. Data analyses were performed using the Epi Info 6.0 statistical program.

\section{Results}

Among the 409 children included in the study, 235 $(57.0 \%)$ were boys and $174(43.0 \%)$ were girls, with a male:female ratio of approximately 1.3:1. Trauma prevalence was highest in the up to 2 years age group $(40.3 \%)$, followed by the $2-3$ year age group $(29.8 \%)$, the $3-4$ year age group $(16.9 \%)$ and the $4-5$ year age group $(13.0 \%)$. The correlation between age and gender was significant (chi-square test $=14.12$; $p=0.0069$ ). Both genders showed a high prevalence for the up to 2 years age group (Table 1 ).

Table 1 - Prevalence of dental injuries according to age group and gender.

\begin{tabular}{c|c|c|c|c|c|c}
\hline \multirow{2}{*}{$\begin{array}{c}\text { Age } \\
\text { (in years) }\end{array}$} & \multicolumn{4}{|c|}{ Gender } & \multicolumn{2}{c}{ Total } \\
\cline { 2 - 5 } & \multicolumn{2}{|c|}{ Male } & \multicolumn{2}{c|}{ Female } & \multirow{2}{*}{$n$} & \multirow{2}{*}{$\%$} \\
\cline { 2 - 6 } & $\mathrm{n}$ & $\%$ & $\mathrm{n}$ & $\%$ & & \\
\hline Up to 2 & $73^{*}$ & 44.2 & $92 *$ & 55.8 & 165 & 100.0 \\
\hline $2-3$ & 65 & 53.3 & 57 & 46.7 & 122 & 100.0 \\
\hline $3-4$ & 21 & 30.4 & 48 & 69.6 & 69 & 100.0 \\
\hline $4-5$ & 16 & 30.2 & 37 & 69.8 & 53 & 100.0 \\
\hline Total & 175 & - & 234 & - & 409 & - \\
\hline
\end{tabular}

*Statistically significant $(p<0.05)$.

Table 3 - Distribution of the number of episodes of dental trauma according to the time period between injury and treatment (Delay).

\begin{tabular}{c|c|c}
\hline Delay & Number & $\%$ \\
\hline 1 day & 188 & 43.5 \\
\hline $2-15$ days & 147 & 34.0 \\
\hline $16-30$ days & 11 & 2.5 \\
\hline$>30$ days & 34 & 8.0 \\
\hline Unknown & 52 & 12.0 \\
\hline Total & 432 & 100.0 \\
\hline
\end{tabular}

The causes of injury for the 432 episodes of dental trauma are outlined in Table 2. Falling caused by walking or running was the etiologic factor most often observed $(37.7 \%)$, followed by falling against objects $(18.8 \%)$.

The time that elapsed until dental care was provided was highest in the period up to 1 day $(43.5 \%)$, followed by $2-15$ days $(34.0 \%)$, as shown in Table 3.

The 432 trauma occurrences involved 679 injured primary teeth. Most of the affected teeth belonged to the maxillary arch $(95.0 \%)$. The maxillary central incisors were most affected (563/679), followed by the maxillary lateral incisors (82/679) and mandibular incisors (28/679). The primary canines were affected in only six cases (Figure 1 ).

Subluxation was the most common type of injury with 221 cases $(32.6 \%)$, followed by intrusive luxation with 202 cases $(29.7 \%)$, as shown in Table 4 . In general, the prevalence of luxation injuries decreased with increasing age $(p=0.045)$ (Figure 2).

Table 2 - Distribution of the number of episodes of dental trauma according to the etiologic factors.

\begin{tabular}{l|r|r}
\hline Etiologic Factors & Number & $\%$ \\
\hline Category 1: Falls & & \\
\hline - Falling while walking or running & 163 & 37.7 \\
\hline - Falling from high objects & 71 & 16.4 \\
\hline - Falling against objects & 81 & 18.8 \\
\hline - Falling from moving objects & 41 & 9.5 \\
\hline Category 2: Other Factors & 18 & 4.2 \\
\hline Unknown & 58 & 13.4 \\
\hline Total & 432 & 100.0 \\
\hline
\end{tabular}

Table 4 - Prevalence of the different types of dental injuries in the total number of affected teeth.

\begin{tabular}{l|c|c}
\hline Type of injury & Number of teeth & $\%$ \\
\hline Subluxation & 221 & 32.6 \\
\hline Intrusive luxation & 202 & 29.7 \\
\hline Lateral luxation & 95 & 14.0 \\
\hline Extrusive luxation & 14 & 2.1 \\
\hline Avulsion & 140 & 20.6 \\
\hline Lateral luxation + intrusive luxation & 7 & 1.0 \\
\hline Total & 679 & 100.0 \\
\hline
\end{tabular}


Figure 1 - Distribution of dental trauma among anterior teeth.

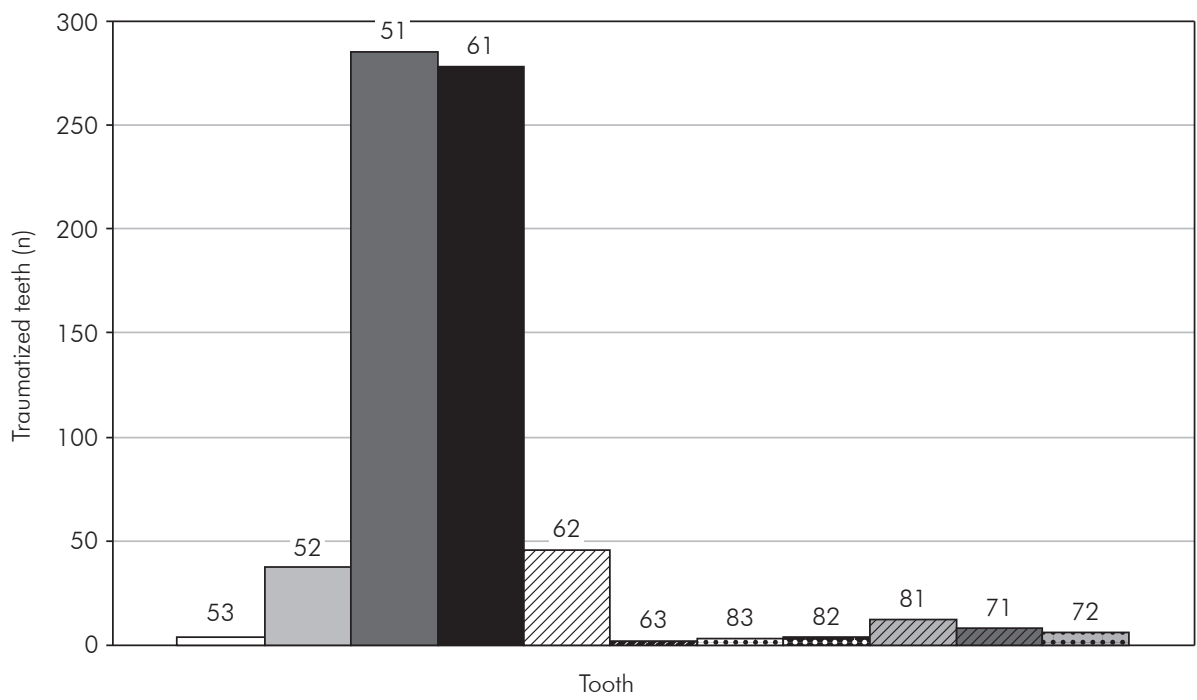

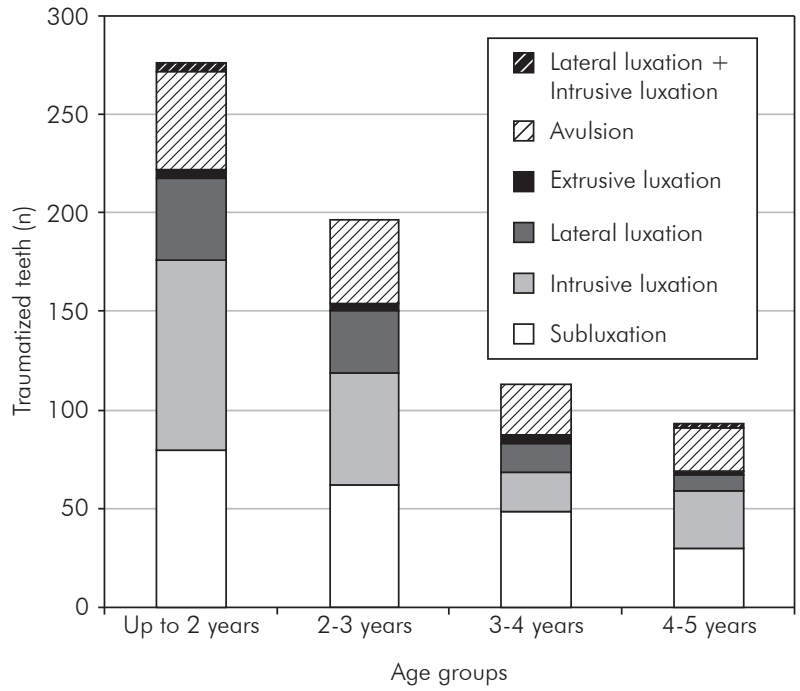

Figure 2 - Association between age groups and the type of dental trauma in primary anterior teeth.

With regard to the treatment provided for injured primary teeth, the most common treatment was "monitor only" (74\%), followed by splinting (9\%) (Figure 3).

Table 5 shows the relationship between the time elapsed before treatment and the type of dental trauma. There was a significant preponderance of injuries in the 1-15 days interval (chi-square test $=17.17 ; p=0.041$.

\section{Discussion}

This study evaluated luxation injuries of primary

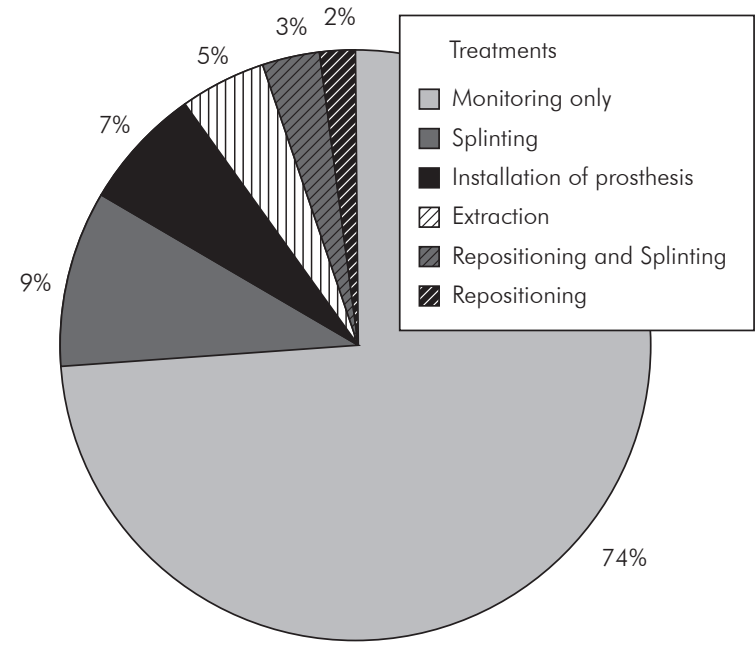

Figure 3 - Distribution of the different types of treatment used for injured primary teeth.

teeth and injury-associated factors in children who were treated at an emergency center. Most of the dental trauma data available in the literature has been collected retrospectively from cross-sectional studies or from longitudinal studies of patient records. ${ }^{6}$ In the current study, the assessment of standardized trauma records with information collected at the time of assistance enabled the authors to obtain more reliable data relative to previous retrospective studies in which injuries were only registered if signs and/or symptoms were evident at the time of examination. 
Table 5 - Distribution of the number of affected teeth according to the type of trauma and two seeking-dental-care periods studied (Delay).

\begin{tabular}{|c|c|c|c|c|c|c|}
\hline \multirow{3}{*}{ Type of Trauma } & \multicolumn{4}{|c|}{ Delay } & \multirow{2}{*}{\multicolumn{2}{|c|}{ Total }} \\
\hline & \multicolumn{2}{|c|}{$1-15$ days* } & \multicolumn{2}{|c|}{$\geq 16$ days } & & \\
\hline & $\mathrm{n}$ & $\%$ & $n$ & $\%$ & $\mathrm{n}$ & $\%$ \\
\hline Subluxation & 178 & 89.0 & 22 & 11.0 & 200 & 100 \\
\hline Intrusive luxation & 162 & 88.5 & 21 & 11.5 & 183 & 100 \\
\hline Lateral luxation & 84 & 93.3 & 6 & 6.7 & 90 & 100 \\
\hline Extrusive luxation & 13 & 100.0 & 0 & 0.0 & 13 & 100 \\
\hline Avulsion & 93 & 77.5 & 27 & 22.5 & 120 & 100 \\
\hline $\begin{array}{l}\text { Lateral luxation + } \\
\text { intrusive luxation }\end{array}$ & 6 & 100.0 & 0 & 0.0 & 6 & 100 \\
\hline Total & 536 & - & 76 & - & 612 & - \\
\hline
\end{tabular}

*Statistically significant $(p<0.05)$

A slight difference was observed between genders affected by dental trauma. There is a consensus among international studies that boys experience significantly more dental injuries to permanent dentition than girls. ${ }^{7,8}$ In primary teeth, however, there does not appear to be a difference between genders. ${ }^{9,10}$ Children between the ages of 1 and 5 years are exposed to the same risk factors, and there is no difference between genders with regard to the games and sports played by this age group. ${ }^{11}$

Previous studies confirm that younger children are more susceptible to dental trauma when they are learning to walk, combined with other behavioral factors, including their curiosity and lack of danger perception; these factors are known to contribute to facial trauma. ${ }^{12,13}$ The findings of the current study, which show a higher percentage of younger children with a history of dental trauma, are in agreement with some studies of children in similar age groups, ${ }^{14-17}$ but are in disagreement with other studies that found increased susceptibility in children between the ages of 3 and 5 years. ${ }^{10,18,19}$ However, careful attention should be paid when comparing studies in the field of dental trauma, as data may vary according to the location where the study is conducted and the type of methodology applied. ${ }^{6,11,20}$

Falls were the most prevalent etiologic factor in traumatized teeth $(82.4 \%)$. This finding is consistent with other studies. ${ }^{15,21,22}$ When considered sepa- rately, falling caused by walking or running was the most prevalent cause of dental trauma $(37.7 \%)$, which disagrees with the findings of Garcia-Godoy et al., ${ }^{9}$ who reported that falling against an object was the most frequent cause of dental injuries.

The reason for the selection of luxation injuries was related to the higher prevalence of these injuries in the study location and the fact that these injuries are the type of trauma most related to sequelae in the permanent teeth. ${ }^{3,23,24}$ Studies have found luxation injuries to be the type of trauma most prevalent in the primary dentition. ${ }^{1}$ In this study, subluxation was the most common type of trauma, which is in agreement with previous reports. ${ }^{16,21}$ Extrusive luxation was the least common type of injury, which is in agreement with studies by Cunha et al. ${ }^{4}$ and Yagot et al., ${ }^{25}$ both of which reported a rate of $1 \%$ for extrusions. In contrast, in a study by Andreasen, ${ }^{26}$ extrusive luxation was the type of trauma most often found in the primary dentition $(34.0 \%)$. In general, the occurrence of luxation injuries decreased with increasing age in the current study, and an increase in the episodes of intrusive luxations was observed from the ages of 3-4 and 4-5 years.

The treatment of trauma to primary teeth is a topic that has only recently found a place in the specialized literature. In cases of luxation, dental extraction has been the treatment of choice. This action is justified, mainly due to the difficulty of handling dental treatment in young children and the damage caused to the germ of the permanent successor. ${ }^{27}$

The therapeutic protocol for traumatized primary teeth at the Baby Clinic at Londrina State University is based on procedures developed since 1986 . This program attempts to provide a more conservative approach to traumatized primary teeth. The findings of the current study reflect this concept, as "monitor only" was the most common treatment among the analyzed cases $(74.0 \%)$. In agreement with the current findings, Cunha et al. ${ }^{28}$ also observed a higher prevalence of "monitor only" $(85.4 \%)$, even for luxation injuries, when evaluating dental trauma among babies and toddlers. In general, the time lapse between injury and treatment played a significant role in the type of treatment, because immediate care can provide a better progno- 
sis for injured teeth. Even so, most luxation injuries heal spontaneously, and conservative treatment of acute dental trauma is recommended. ${ }^{29}$

With regard to the time lapse between injury and treatment, most of the cases fell into the category of " 1 day," which is in agreement with the results of previous studies. ${ }^{5,14,21}$ The time spent by parents seeking assistance was strongly related to their educational background and the information available to them regarding dental care services. ${ }^{8}$ In a study of traumatized permanent teeth, Zaitoun et al. ${ }^{30}$ found a mean time of 22.6 hours from the time of injury until initial presentation to a health care professional. Based on their findings, they emphasized a need for educational programs and clinical support when services are provided.

More severe trauma generally resulted in slicing of the soft tissue and bleeding, which increased the anxiety among parents or guardians ${ }^{21,26}$ and led them to seek treatment more quickly. In the current study, there was a statistically significant relationship between the type of trauma and the time period between injury occurrence and treatment, with a higher prevalence for the period "1-15 days" for all evaluated trauma. Pugliesi et al. ${ }^{5}$ analyzed hard-

\section{References}

1. Andreasen JO, Andreasen FM, Andersson L. Text book and color atlas of traumatic injuries to the teeth. $4^{\text {th }}$ ed. Oxford: Blackwell Munsksgaard; 2007. 770 p.

2. Joho JP, Marechaux SC. Trauma in the primary dentition: a clinical presentation. ASDC J Dent Child. 1980 MayJun;47(3):167-74.

3. Da Silva Assunção LR, Ferelle A, Iwakura ML, Cunha RF. Effects on permanent teeth after luxation injuries to the primary predecessors: a study in children assisted at an emergency service. Dent Traumatol. 2009 Apr;25(2):165-70.

4. Cunha RF, Pugliesi DMC, de Mello Vieira AE. Oral trauma in Brazilian patients aged 0-3 years. Dent Traumatol. 2001 Oct;17(5):210-2.

5. Pugliesi DM, Cunha RF, Delbem AC, Sundefeld ML. Influence of the type of the dental trauma on the pulp vitality and the time elapsed until treatment: a study in patients aged 0-3. Dent Traumatol. 2004 Jun;20(3):139-42.

6. Bastone EB, Freer TJ, McNamara JR. Epidemiology of dental trauma: a review of the literature. Aust Dent J. 2000 Mar;45(1):2-9. tissue injuries and supporting-tissue lesions and also found a statistically significant relationship between the type of dental trauma and the time until treatment was sought: worse trauma promoted a quicker response to seeking treatment. The results of the current study showed that treatment usually occurred within the first 15 days after the injury.

\section{Conclusions}

The most frequent type of injury occurred on the maxillary central incisors of children in the "up to two years" age group. In general, the prevalence of luxation injuries decreased with increasing age. Boys suffered from dental trauma significantly more often than girls. Falling as a result of walking or running was the most common etiologic factor. Subluxation was the most common type of trauma. Treatment usually occurred within the first 15 days after the injury. Despite the severity of these injuries, "monitor only" was the most common treatment.

\section{Acknowledgement}

This work was supported by a Brazilian research funding agency (CAPES).

7. Altun C, Ozen B, Esenlik E, Guven G, Gürbüz T, Acikel C, et al. Traumatic injuries to permanent teeth in Turkish children, Ankara. Dent Traumatol. 2009 Jun;25(3):309-13.

8. Onetto JE, Flores ML, Garbarino ML. Dental trauma in children and adolescents in Valparaiso, Chile. Endod Dent Traumatol. 1994 Oct;10(5):223-7.

9. García-Godoy F, Morbán-Laucer F, Corominas LR, Franjul RA, Noyola M. Traumatic dental injuries in preschoolchildren from Santo Domingo. Community Dent Oral Epidemiol. 1983 Apr;11(2):127-30.

10. Kramer PF, Zembruski C, Ferreira SH, Feldens CA. Traumatic dental injuries in Brazilian preschool children. Dent Traumatol. 2003 Dec;19(6):299-303.

11. Wendt FP, Torriani DD, Assunção MC, Romano AR, Bonow ML, da Costa CT, et al. Traumatic dental injuries in primary dentition: epidemiological study among preschool children in South Brazil. Dent Traumatol. 2010 Apr;26(2):168-73.

12. Moss SJ, Maccaro H. Examination, evaluation and behavior management following injury to primary incisors. N Y State Dent J. 1985 Feb;51(2):87-92. 
13. Diab M, Elbadrawy HE. Intrusion injuries of primary incisors. Part I: review and management. Quintessence Int. 2000 May;31(5):327-34.

14. Cardoso M, de Carvalho Rocha MJ. Traumatized primary teeth in children assisted at Federal University of Santa Catarina, Brazil. Dent Traumatol. 2002 Jun;18(3):129-33.

15. Fleming P, Gregg TA, Saunders IDF. Analysis of an emergency dental service provided at a children's hospital. Int J Paediatr Dent. 1991 Apr;1(1):25-30.

16. Galea H. An investigation of dental injuries treated in an acute care general hospital. J Am Dent Assoc. 1984 Sep;109(3):434-8.

17. Rasmusson CG, Koch G. Assessment of traumatic injuries to primary teeth in general practice and specialized paediatric dentistry. Dent Traumatol. 2010 Apr;26(2):129-32.

18. Granville-Garcia AF, de Menezes VA, de Lira PIC. Dental trauma and associated factors in Brazilian preschoolers. Dent Traumatol. 2006 Dec;22(6):318-22.

19. Skaare AB, Jacobsen I. Primary tooth injuries in Norwegian children (1-8 years). Dent Traumatol. 2005 Dec;21(6):315-9.

20. Oliveira LB, Marcenes W, Ardenghi TM, Sheiham A, Bönecker M. Traumatic dental injuries and associated factors among Brazilian preschool children. Dent Traumatol. 2007 Apr;23(2):76-81.

21. Choi SC, Park JH, Pae A, Kim JR. Retrospective study on traumatic dental injuries in preschool children at Kyung Hee Dental Hospital, Seoul, South Korea. Dent Traumatol. 2010 Feb;26(1):70-5.
22. Harrington MS, Eberhart AB, Knapp JF. Dentofacial trauma in children. ASDC J Dent Child. 1988 Sep-Oct;55(5):334-8.

23. Andreasen JO, Ravn JJ. The effect of traumatic injuries to primary teeth on their permanent successors. II. A clinical and radiographic follow-up study of 213 teeth. Scand J Dent Res. 1971;79(4):284-94.

24. Brin I, Fuks A, Ben Bassat Y, Zilberman Y. Trauma to the primary incisors and its effect on the permanent successors. Pediatr Dent. 1984 Jun;6(2):78-82.

25. Yagot KH, Nazhat NY, Kuder SA. Traumatic dental injuries in nursery schoolchildren from Baghdad, Iraq. Community Dent Oral Epidemiol. 1988 Oct;16(5):292-3.

26. Andreasen JO. Etiology and pathogenesis of traumatic dental injuries. A clinical study of 1,298 cases. Scand J Dent Res. 1970;78(4):329-42.

27. Borum MK, Andreasen JO. Sequelae of trauma to primary maxillary incisors. I. Complications in the primary dentition. Endod Dent Traumatol. 1998 Feb;14(1):31-44.

28. Cunha RF, Pugliesi DMC, Percinoto C. Treatment of traumatized primary teeth: a conservative approach. Dent Traumatol. 2007 Dec;23(6):360-3.

29. Flores MT. Traumatic injuries in the primary dentition. Dent Traumatol. 2002 Dec;18(6):287-98.

30. Zaitoun H, North S, Lee S, Albadri S, McDonnel ST, Rodd HD. Initial management of paediatric dento-alveolar trauma in the permanent dentition: a multi-centre evaluation. Br Dent J. 2010 Mar;208(6):E11. 